\title{
Temperature response of rhodamine B-doped latex particles. From solution to single particles
}

\author{
Antonin Soleilhac, ${ }^{a}$ Marion Girod, ${ }^{b}$ Philippe Dugourd, ${ }^{a}$ Béatrice Burdin, ${ }^{c}$ Julien Parvole, ${ }^{d}$ \\ Pierre-Yves Dugas, ${ }^{d}$ François Bayard, ${ }^{d}$ Emmanuel Lacôte, ${ }^{e}$ Elodie Bourgeat-Lami ${ }^{d} *$ and \\ Rodolphe Antoine ${ }^{a} *$
}

${ }^{a}$ Institut lumière matière, UMR5306 Université Claude Bernard Lyon1-CNRS, Université de Lyon 69622 Villeurbanne cedex, France.rodolphe.antoine@univ-lyon1.fr

${ }^{b}$ Institut des Sciences Analytiques, UMR 5280 CNRS Université Lyon1, 5 Rue de la Doua, 69100Villeurbanne, FRANCE.

${ }^{c}$ Centre Technologique des Microstructures, Université Claude Bernard Lyon1, Bâtiment Darwin B, 5 rue Raphaël Dubois, 69622 Villeurbanne Cedex, France

${ }^{d}$ Université de Lyon, Univ. Lyon 1, CPE Lyon, CNRS, UMR 5265, Laboratoire de Chimie, Catalyse, Polymères et Procédés (C2P2), 43, Bd. du 11 Novembre 1918, F-69616 Villeurbanne, France. elodie.bourgeat@lcpp.cpe.fr

${ }^{e}$ Hydrazines, et Composés Energétiques Polyazotés (LHCEP), UMR 5278, CNRS, UCBL, CNES, HERAKLES-SAFRAN, Bâtiment Berthollet, 22 Avenue Gaston Berger, 69622 Villeurbanne Cedex, France

\section{Supporting Information}




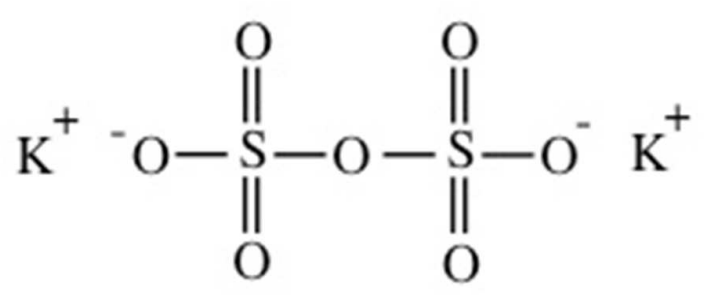

Figure S1. Chemical structure of potassium persulfate. 


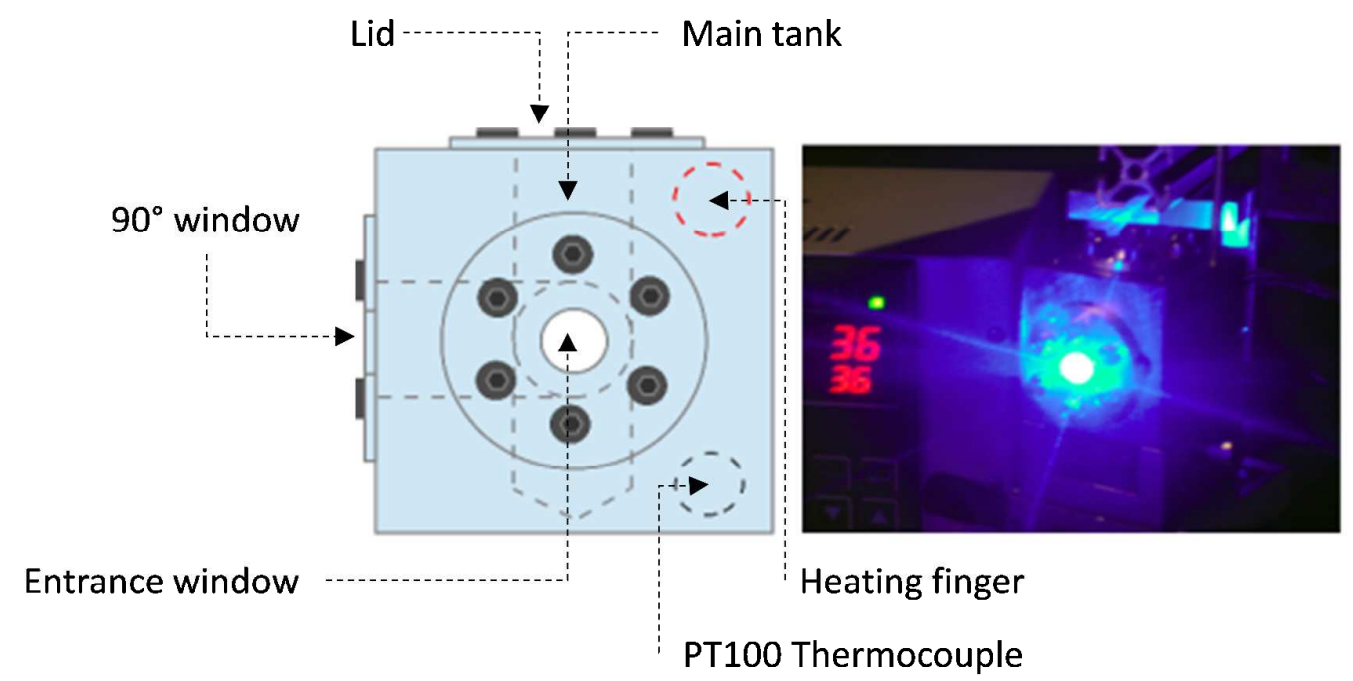

Figure S1. Design and photo of the temperature-controlled cell used in this work. 


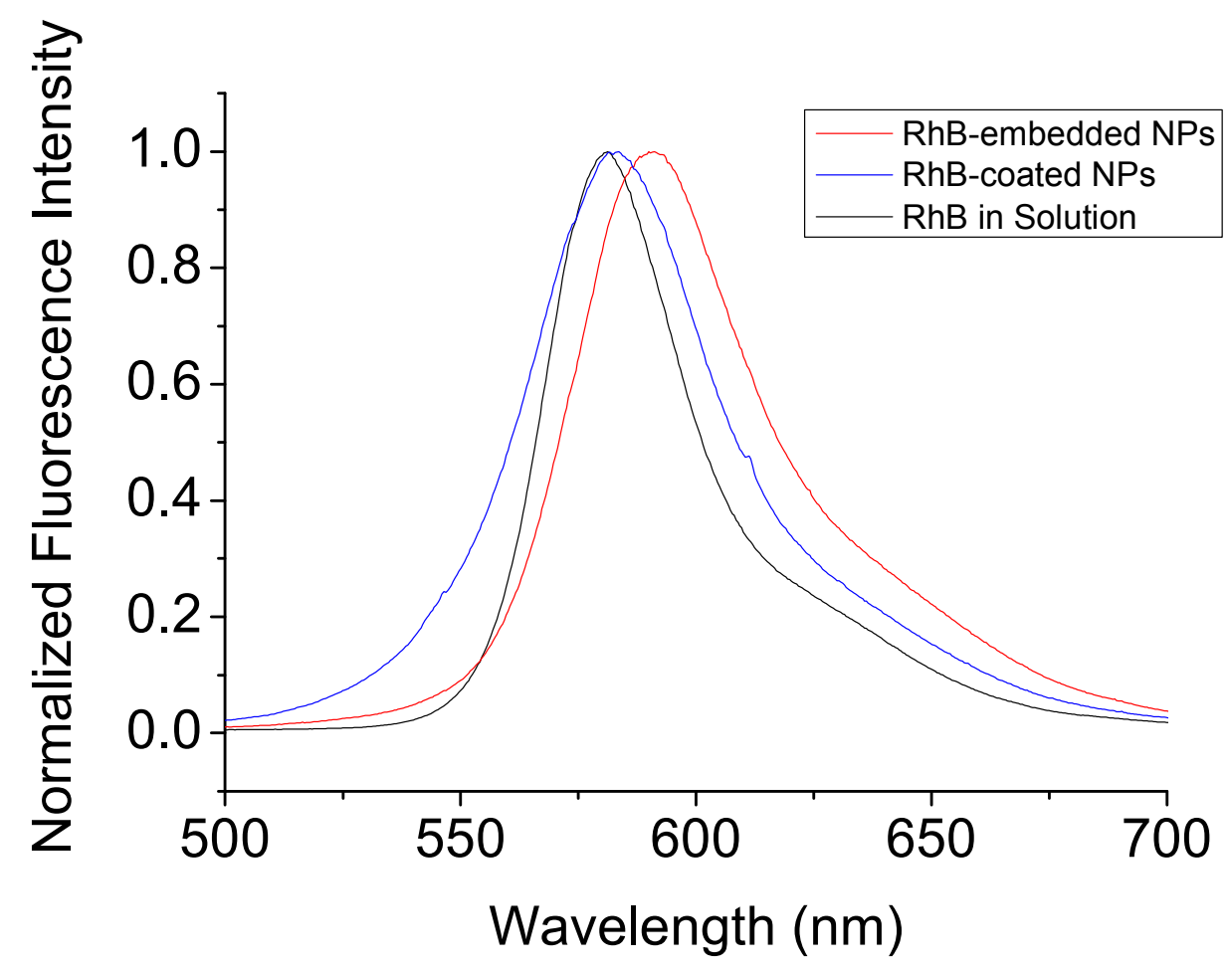

Figure S3. Fluorescence emission spectra of free RhB dye and RhB-doped NPs in water. The corresponding fluorescence liftimes are $1.82 \mathrm{~ns}$ for free RhB dye, $1.67 \mathrm{~ns}$ for RhB-embedded and $0.95 \mathrm{~ns}$ for RhB-coated NPs. Luminescence decay curves were collected with the timecorrelated single-photon counting (TCSPC) extension of fluoromax-4 Horiba fluorescence spectrophotometer using a nano-led source $(370 \mathrm{~nm})$. 

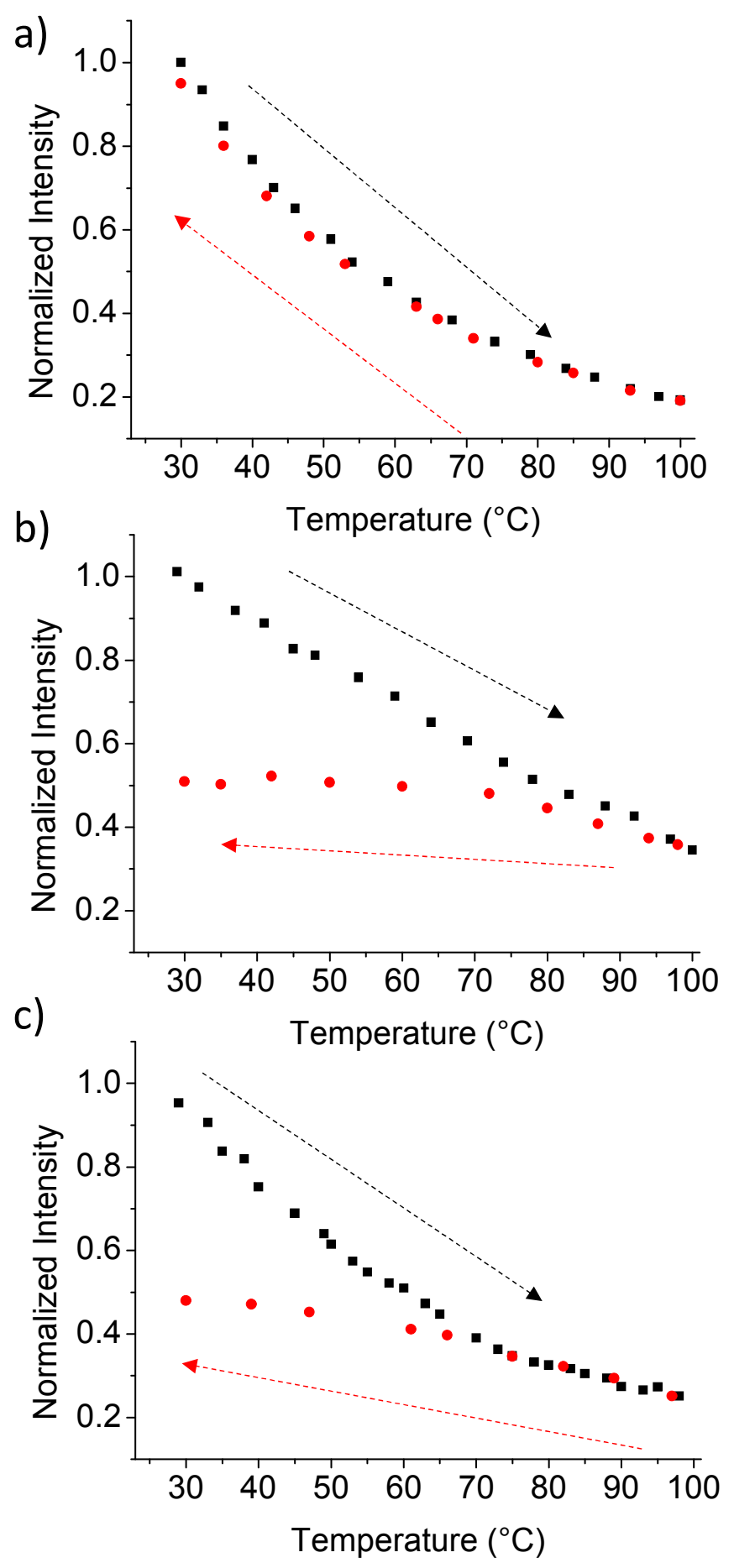

Figure S4. Fluorescence intensity when increasing (black) then decreasing (red) the temperature of a) RhB in aqueous solution b) RhB-embedded NPs and c) RhB-coated NPs dispersed in water in the temperature range $30-100^{\circ} \mathrm{C}$. (Acquisition time for the heatingcooling cycle $\sim 2 \mathrm{~h}$ ). 

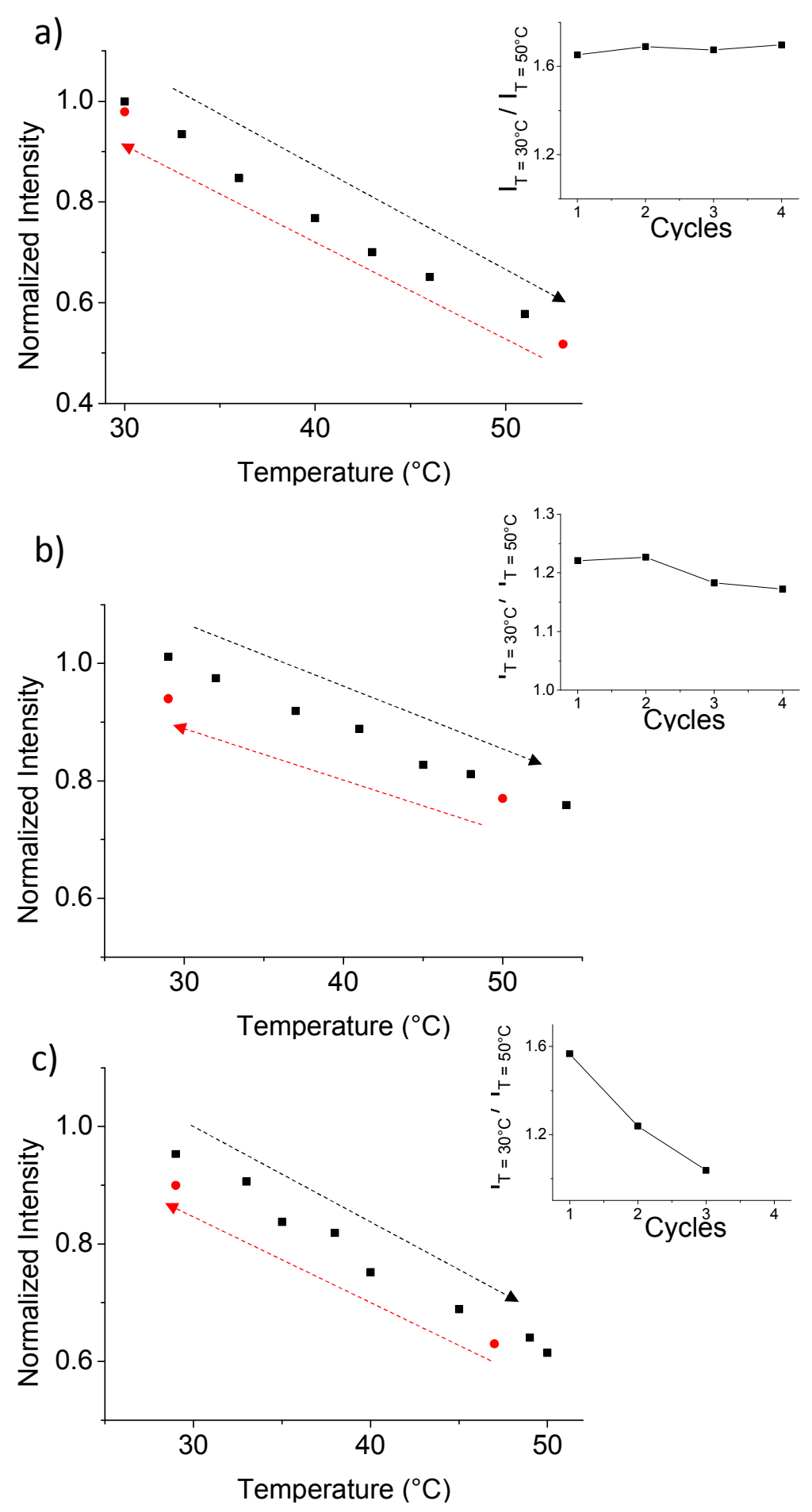

Figure S5. Fluorescence intensity when increasing (black) then decreasing (red) the temperature of a) RhB in aqueous solution b) RhB-embedded NPs and c) RhB-coated NPs dispersed in water in the temperature range $30-50^{\circ} \mathrm{C}$. The reversibility is explored (inset) for 4 cycles in the temperature range $30-50^{\circ} \mathrm{C}$ (Acquisition time for one heating-cooling cycle 1h). 

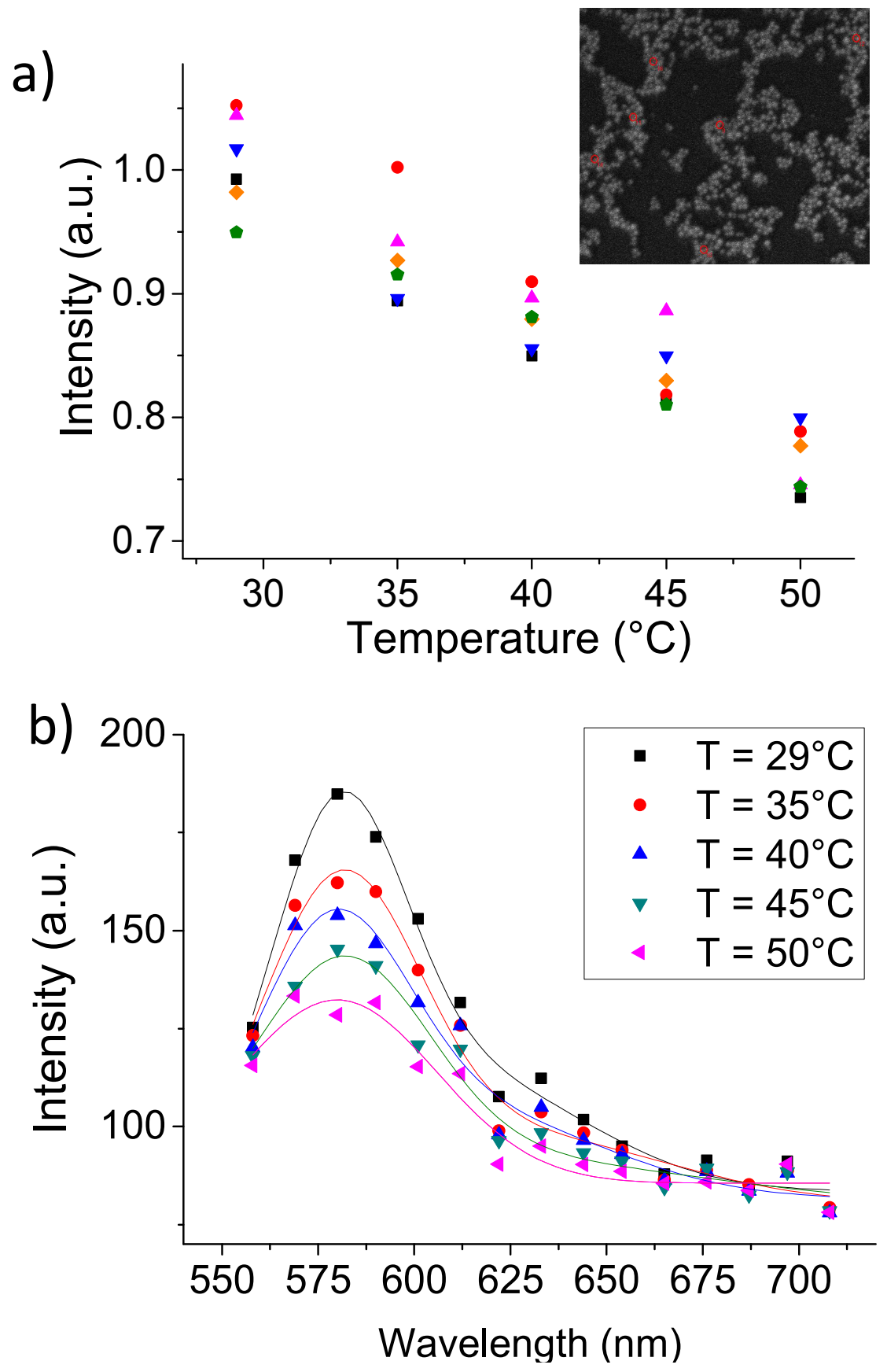

Figure S6. a) Intensity of fluorescence as a function of the temperature in the temperature range $29-50{ }^{\circ} \mathrm{C}$ for 6 individual $\mathrm{RhB}$-embedded latex particles displayed in inset. b) Evolution with the temperature of the fluorescence spectrum in the temperature range 30-50 ${ }^{\circ} \mathrm{C}$, for a single NP. Spectra have been obtained by integrating the signal over the whole Point Spread Function (PSF) and summing the signal along the $\mathrm{z}$ axis with an "open" pinhole. 


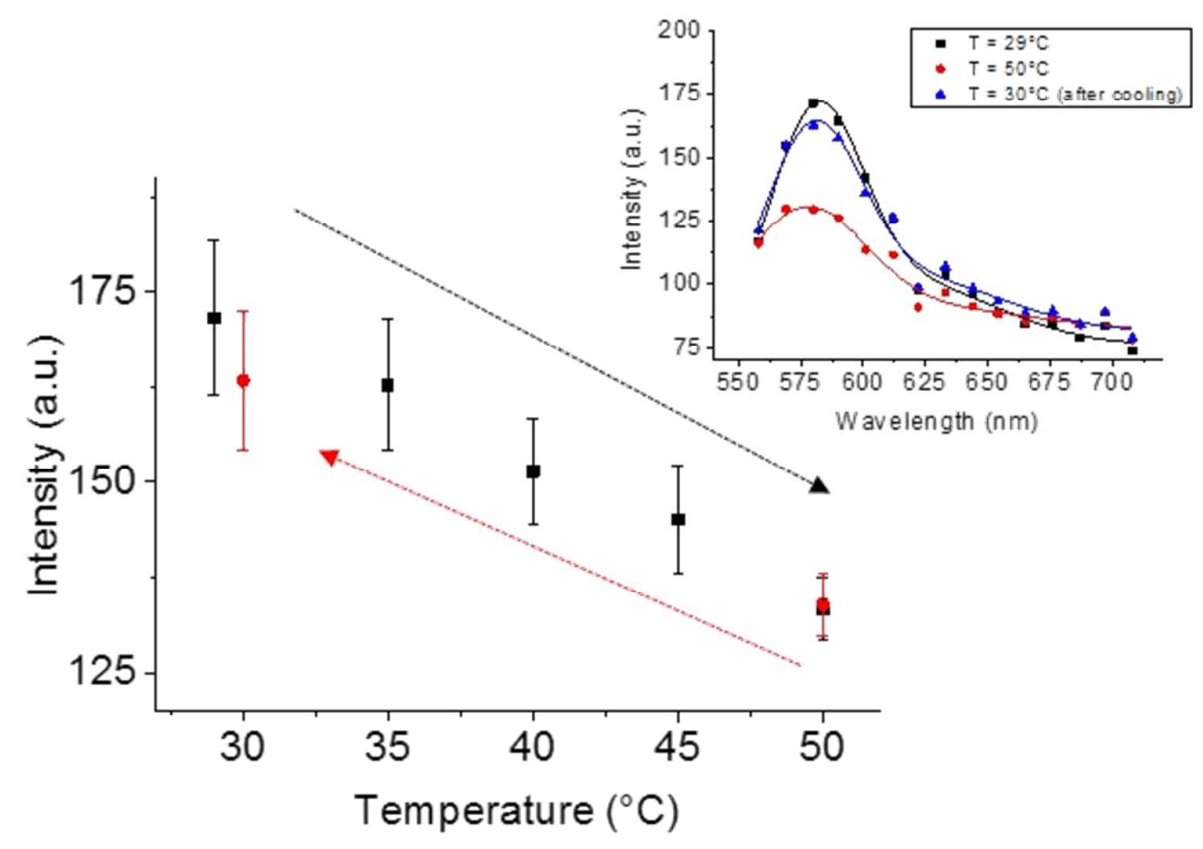

Figure S7. Average fluorescence intensity, over 6 NPs (displayed in inset fig. S6) when increasing (black) then decreasing (red) the temperature. Inset. Fluorescence spectra at $30{ }^{\circ} \mathrm{C}$ and $50{ }^{\circ} \mathrm{C}$ during heating, and at $30^{\circ} \mathrm{C}$ after cooling, for a single NP. 